\title{
Knowledge of Family Planning and Access to Sexual and Reproductive Health Services by Immigrant Youth in Hillbrow, South Africa: A Cross- sectional Study.
}

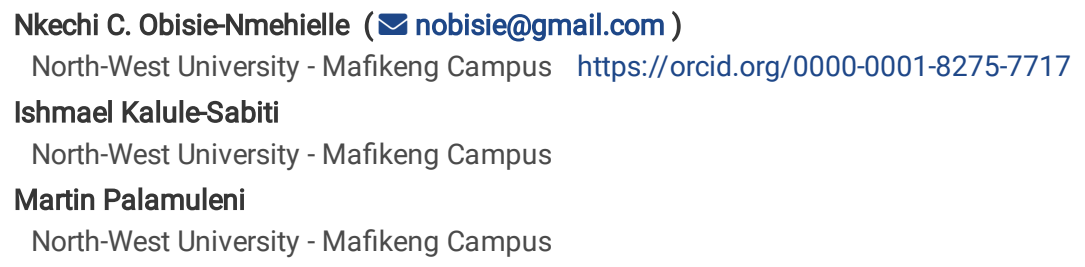




\section{Abstract}

Background: For countries to achieve the Sustainable Development Goals (SDGs) especially SDG3.7- universal access to Sexual and Reproductive Health $(\mathrm{SRH})$ care services including information and education for family planning, immigrant youth must be ensured access to SRH services. This study examines the determinants of knowledge about family planning (KFP) and access to SRH services by sexually active immigrant youth in Hillbrow, South Africa.

Methods: This cross-sectional study of 467 immigrant youth aged 18-34 years used a multistage-sampling technique. Data were collected using interviewer-administered questionnaires on socio-demographic, migration, KFP and access to SRH services from government health facilities. Unadjusted and adjusted logistic regression models were used to determine levels of KFP and access to SRH services among 437 sexually active youth.

Results: The main sources of information on SRH issues were radio/television (38.7\%) and friends (22.8\%). Over half of the respondents have adequate KFP, while two out of five indicated a lack of access to SRH services from government health facilities. In the adjusted models, the determinants of having KFP were being a female $(\mathrm{AOR}=3.85, \mathrm{Cl}$ : $2.33-6.35$, belonging to the age groups $25-29$ years $(\mathrm{AOR}=2.13, \mathrm{Cl}$ : 1.12-4.04; and 30-34 years $(\mathrm{AOR}=3.88, \mathrm{Cl}$ : 2.00-7.53); belonging to the middle and rich wealth index ( $\mathrm{AOR}=1.84, \mathrm{Cl}: 1.05-3.20)$ and ( $\mathrm{AOR}=2.61$ (1.34-5.08) respectively. Not having received information about family planning $(\mathrm{AOR}=0.16, \mathrm{Cl}=0.09-0.28)$ and not using a contraceptive at the time of the survey $(\mathrm{AOR}=0.36, \mathrm{Cl}$ : $0.18-0.70)$ were associated with reduced odds of KFP. The determinants of having access to government health facility for SRH services were being a female (AOR=2.95, $\mathrm{Cl}$ : 1.87-4.65), being 30-34 years of age ( $\mathrm{AOR}=1.91, \mathrm{Cl}$ : $1.08-3.39)$, and not having received information about family planning $(\mathrm{AOR}=0.44, \mathrm{Cl}=0.27-$ $0.73)$.

Conclusion: Majority of the survey respondents lack access to information about family and SRH services provided by government health facilities, which resulted in them depending on unreliable sources of information about SRH issues. There is a need to advocate for universal access to SRH services, inclusive of immigrant youth in South Africa, to curb negative SRH outcomes and to achieve SDG 3.7.

\section{Plain English Summary}

In order to achieve the Sustainable Development Goal (SDG) of universal access to sexual and reproductive health (SRH), sexually active immigrant youth are a vulnerable population in need of access to information, knowledge, and sexual and reproductive health (SRH) services. This study was conducted to understand the factors that determine the KFP and access to government health facilities for SRH services among 439 sexually active immigrant youth in Hillbrow, South Africa. Interviewer-administered questionnaires were used to collect information on the socio-demographic, migration characteristics, KFP and access to health services. The findings show that radio/television and friends were the main sources of information on SRH issues. Almost half of the respondents lacked adequate KFP and only $42 \%$ had access to government health facilities for SRH services. Females had a better KFP than the males, and they had more access to health services than the men. Being older in age, having more household possession, having received information about family planning prior to the survey and using a contraceptive at the time of the survey are also associated with KFP planning and access to health services. It is important to make access to SRH information and services available to immigrant youth to prevent unplanned pregnancies, unsafe abortions, illness, and death among all youth; and to achieve the SDG on universal access to SRH services.

\section{Background}

Access to SRH services by adolescents and youth has been a serious public health concern globally since the Cairo Conference in 1994 [1]. The Colombo Declaration on Youth [2] and the Sustainable Development Goals (SDGs) 2030 Agenda, especially targets 3.7 and 5.6 [3] recommended universal access to SRH services and information for youth with the pledge of "leaving no one behind" [3]. The importance of universal access to SRH care among the youth, including access to SRH education and information are core to ensuring that young people, especially young women, can make informed choices about when to have children and prevention of sexually transmitted diseases [4]. Despite these global commitments and targets, it appears that policies and programmes at global, regional, and national levels continue to leave immigrant youth behind, though they are worse affected by negative SRH issues.

There is growing concern about international migration among policy makers, and researchers globally because of the increased number, with an estimated 272 million accounting for $3.5 \%$ in 2019 . This concern is heightened by the growing number of immigrant youth comprising adolescents and young adults aged 15-24, as well as older youth from $25-34$ years of age. In 2019 , immigrant youth aged $15-34$ years accounted for $32 \%$ of all international migrants globally [5]. In South Africa, immigrant youth aged $18-34$ years accounted for $29.4 \%$ of all international migrants and $9.2 \%$ of all youth from 18-34 years of age in South Africa in 2019 [5]. In Hillbrow, a densely-populated and immigrant-dense urban suburb of Johannesburg, immigrant youth from 18-34 years of age accounted for $46.4 \%$ of total youth population in 2011 [6]. Immigrants however differ in their migration statusthe documented, the asylum seekers and the undocumented. Documented immigrants are those who are in possession of documents necessary to prove their regular status in the country and are authorized to enter and to stay pursuant to the law of the State [7]. Asylum seekers are those with a Section 22 permit, which allows them to remain in the country temporarily whilst their claim is being processed within six months. If the claim is accepted, they will be awarded a refugee status. Those whose asylum claims are rejected have the opportunity to appeal to the Refugee Appeal Board. If the appeal is rejected again, the applicants were expected to leave the country and those who remain become undocumented [8]. An undocumented immigrant is one who 
enters or stays in a country without the appropriate documentation that proves their right to enter and stay in the country, or such documentation is fraudulent or no longer valid [7].

Despite the growing population of immigrant youth in South Africa, specifically in Hillbrow-an urban suburb with the highest population of immigrants in Johannesburg-little is known about their KFP and their sources of information on SRH issues. Furthermore, there is scant evidence on access to government facilities for SRH services by sexually active immigrant youth in Hillbrow. Based on the Behavioural Model of Health Service Utilization (BMHSU) and the modified model on health service utilization among immigrants, [9-10], this paper examined the determinants of KFP and access to government health facilities for SRH services among sexually active immigrant youth in Hillbrow.

\section{Literature review}

Researchers globally have examined barriers and facilitators of KFP and access to SRH services by immigrant youth [11-12]). Factors influencing KFP and access to health care services include individual factors such as gender, age, level of education and wealth index [13] and migration status [14-15]. Other factors include experiences of discrimination and lack of social support [16-18]; attitude of health care practitioners [12, 19-20].

Previous studies from South Africa used qualitative studies $[8,21]$ and narrative review [22] to document the barriers experienced by immigrants in accessing SRH services. Some of the barriers identified include socio-cultural and financial barriers; negative attitudes from health professionals, economic dependency, and lack of documentation [21-22]. Richter and colleagues [23] found low levels of health service utilization among immigrant female sex workers as compared to non-migrants and internal migrants in the three South African cities used for their study.

Increased international migration, health risks, as well as the increasing number of undocumented migrants have heightened concerns about immigrants. South Africa is committed to the SDGs, especially SDG 3.7 on universal access to SRH services. The country's laws, policies, and guidelines "are progressive and comprehensive on contraceptive service provision in the public sector; and promote integrated, rights-based service delivery" [24]. Negative consequences of poor SRH outcomes-such as unplanned and unwanted pregnancies, HIV/AIDS, STIs, maternal mortality and infertility-affect the development indicators of the country. In order to curb the negative SRH outcomes among the entire population, access to health facilities for information on family planning and other SRH-related services is vital for all youth, irrespective of immigration status.

The main objective of this study was to determine the factors associated with KFP and access to SRH services in government health facilities by immigrant youth in Hillbrow, South Africa.

\section{Methods}

\section{Study setting}

The study took place in Hillbrow, a densely populated area in a residential suburb in the inner city of Johannesburg. Hillbrow is a suburb for many people in transit, with a significantly high population density of immigrants-a melting pot of internal migrants from different provinces in South Africa as well as immigrants from different countries. Based on the South African Census 2011 [6], Hillbrow has a total population of 74,131, 24,857 households, and a population density of $68,418.11$ per $\mathrm{km}^{2}$.

\section{Study population}

The participants for the study were selected from a population of consenting male and female immigrant youth, 18-34 years of age, residing in selected households in Hillbrow in 2019.

\section{Study design}

A cross-sectional study which involved a household survey conducted in Hillbrow in December 2019 using structured interviewer-administered questionnaires. Data on background information such as individual sociodemographic characteristics; migratory history, knowledge of SRH and access to SRH services were collected from respondents.

\section{Sample size}

The sample size for frequency in a population with a correction factor was used to calculate the sample size of immigrant youth needed for this study to account for the effect of intra-cluster correlation. The design effect of 1.25 was used to correct for estimated sample variance and account for within group differences among the respondents. The determination of sample size involved multi-stage sampling technique. Using simple random technique, 9 of the enumeration areas (EAs) were selected out of the 30 EAs in Hillbrow. A full list of all the streets in the selected EAs was mapped, and this formed the sampling frame for the study. Using a simple random sampling technique, a list was drawn from the sampling frame and the streets drawn were the location of the study. The dwelling units in the selected streets were not randomly selected due to security challenge in getting access to some of the properties. In dwelling units where access was given, a flat was randomly selected as a starting point and every $10^{\text {th }}$ flat was visited. When a flat

Page 3/11 
contained two or more households, then only one respondent per household was included. The questionnaire was administered to male and female immigrants from 18-34 years of age. A total of 467 immigrants responded to the survey.

\section{Study instrument}

The questionnaire was structured into themes to capture the different characteristics such as sociodemographic, sexual behaviour, knowledge, and information about SRH and migration characteristics of the respondents. Most of the questions were adapted from the survey questionnaire by the African Population and Health Research Centre (APHRC) and the 2016 South African Demographic and Health Survey [25-26], after an extensive literature review. The questionnaire was pilot tested and revised before the field work was undertaken.

\section{Survey measures}

\section{Outcome variables}

The outcome variables measured were KFP and access to government health facility for SRH services. KFP was assessed from two variables. The first variable was having heard of a family planning method. The question asked was "Have you ever heard of any of these family planning methods?" The contraceptive methods listed were daily pill, intrauterine device (IUD), male condom, female condom, injectable/Depo-Provera, implants, emergency contraception, vasectomy, and tubal ligation. A "Yes" or "No" response was provided for each contraceptive method. The second variable was knowledge of place to obtain a contraceptive method. The question asked was "Do you know a place in this area where you can obtain any of the following family planning method?" The contraceptive methods listed were daily pill, IUD, male condom, female condom, injectable/Depo-Provera, implants, emergency contraception, vasectomy, and tubal ligation. A "Yes" or "No" response was also provided for each contraceptive method. Factor analyses were done on the variables "Having heard of a family planning method" and "Knowledge of where to obtain a family planning method". The new variables generated were "Heard of contraceptive method" and "Know place to obtain a contraceptive method". These new variables had Yes/No responses. These two variables were re-classified and used to generate the variable "Knowledge of family planning" with a "Inadequate knowledge" or "Adequate knowledge" categories.

The second outcome variable was access to SRH services provided by a government health facility. The question asked was: "Have you visited any government clinic/health facility in this area for SRH services? This had a Yes/No response.

\section{Explanatory variables}

The explanatory variables include variables on sociodemographic, migration and SRH characteristics. The sociodemographic variables examined in this study were gender identified as biological male or female. Age in completed years was further categorised in groups from 18-24, 25-29, and 30-34. Highest level of education attained was categorised as incomplete primary, complete primary, incomplete secondary, complete secondary/matric, incomplete tertiary education (technikon/university), completed tertiary and post-graduate education. Incomplete primary and complete primary were combined and recoded as "Primary"; incomplete secondary and complete secondary/matric were combined and recoded as "Secondary", while incomplete tertiary education (technikon/university), complete tertiary and post-graduate education were combined and recoded as "Tertiary". Marital status was classified into single, which include those who are not in union (never married/separate/divorced) and married, which include those who are married or cohabiting. With regards wealth index, this was derived using principal component analysis of several household ownerships. The variable generated was categorised into poor, middle and rich quintiles. In order to assess the sources of information on SRH issues, respondents were asked about their sources of information. The options listed were posters, television/radio, health centre/community clinic, private clinic, government hospital, parents, peer educators, teachers, and friends. Each had a Yes/No option.

Migration status was assessed by asking the respondent about his/her current migration status in South Africa. The options listed were naturalised South African citizen, permanent resident, work permit, study permit, refugee, asylum seeker, no paper (undocumented). These were then categorised as documented (South African citizen, permanent resident, work permit, study permit, refugee), asylum seekers and undocumented. The second migration variable was to assess experiences of discrimination in the neighbourhood. The question asked was "Have you ever experienced discrimination since you came to Hillbrow?" The options were Never, Sometimes, Often, Always and No response. This variable was classified into a Yes or No. The last migration variable was social support in South Africa. The question asked was "Do you have anyone here in South Africa who you trust and with whom you can discuss very important and private issues?" This question has a Yes or No response. Respondents were further asked if they received information about family planning. The question asked was "Have you received any information in the past six months about family planning specifically? This had a Yes or No response. The last explanatory variable was about current use of a family planning method. The question asked was "Are you or your partner currently doing anything or using any method to delay or avoid getting pregnant?" This had a Yes or No response.

\section{Data analysis}


Data analysis was conducted using STATA MP 14.1. Bivariate logistic regression analysis was done to get the crude (unadjusted) odd ratios with p-value set at $\mathrm{p} \leq 0.05$, and $95 \%$ confidence interval. The bivariate analyses showed the association between the outcome variables and each of the explanatory variables. Multivariate logistic regression (adjusted odds ratio) was carried out to determine the factors predicting the outcome variables in the adjusted models. Separate models were used for male, female, and total respondents in order to show gender differences in the outcome variables. The adjusted model combined all the significant variables at bivariate level. The results are tabulated for presentation.

\section{Results}

The background characteristics of 467 immigrant youths are summarised in Table 1 at the end of the document. About two out of five respondents were males, while three out of five were females. The respondents in the age group from 18-24 years constituted $43 \%$ of the total sample. Almost seven out of 10 have completed secondary education or higher, $65 \%$ were not married, while $39 \%$ were in the poor wealth quintile while only $25 \%$ were in the rich wealth quintile. With regards current migration status, only a third of the immigrant youth in Hillbrow reported being documented, over one out of five reported themselves as asylum seekers, while over two out of five were undocumented. Over half of the respondents reported having experienced discrimination in Hillbrow. With regards to sexual and reproductive health characteristics, $94 \%$ of the respondents had engaged in sexual intercourse at the time of the survey, three out of five respondents had information about family planning six months prior to the survey. Among the males, however, only two out of five had recent information about family planning. Regarding current use of contraception, four out of five reported that they were using a contraceptive method at the time of the survey.

Table 1

Background characteristics of immigrant youth in Hillbrow, South Africa 


\begin{tabular}{|c|c|c|c|}
\hline Variable & $\begin{array}{l}\text { Total } \\
(\mathrm{N}=467)(\%)\end{array}$ & $\begin{array}{l}\text { Male } \\
(n=193)(\%)\end{array}$ & $\begin{array}{l}\text { Female } \\
(n=274)(\%)\end{array}$ \\
\hline \multicolumn{4}{|l|}{ Gender } \\
\hline Male & $193(41.3)$ & & \\
\hline Female & $274(58.7)$ & & \\
\hline \multicolumn{4}{|l|}{ Age group } \\
\hline $18-24$ & $199(42.6)$ & $80(41.4)$ & $119(43.4)$ \\
\hline $25-29$ & $127(27.2)$ & $48(24.9)$ & $79(28.8)$ \\
\hline $30-34$ & $141(30.2)$ & $65(33.7)$ & $76(27.7)$ \\
\hline \multicolumn{4}{|l|}{ Highest level of education attained } \\
\hline Primary/incomplete secondary & $147(31.5)$ & $61(31.6)$ & $86(31.4)$ \\
\hline Complete Secondary/Higher & $320(68.5)$ & $132(68.4)$ & $188(68.6)$ \\
\hline \multicolumn{4}{|l|}{ Marital status } \\
\hline Single & $302(64.7)$ & $128(66.3)$ & $174(63.5)$ \\
\hline Married/Cohabiting & $165(35.3)$ & $65(33.7)$ & $100(36.5)$ \\
\hline \multicolumn{4}{|l|}{ Wealth index } \\
\hline Poor & $182(39.0)$ & $82(42.5)$ & $100(36.5)$ \\
\hline Middle & $169(36.2)$ & $62(32.1)$ & $107(39.1)$ \\
\hline Rich & $116(24.8)$ & $49(25.4)$ & $67(24.4)$ \\
\hline \multicolumn{4}{|l|}{ Migration status } \\
\hline Documented & $158(33.8)$ & $60(31.1)$ & $98(35.8)$ \\
\hline Asylum seeker & $102(21.9)$ & $36(18.6)$ & $66(24.1)$ \\
\hline Undocumented & $207(44.3)$ & $97(50.3)$ & $110(40.1)$ \\
\hline \multicolumn{4}{|l|}{ Discrimination in Hillbrow } \\
\hline Yes & $265(56.8)$ & $111(57.5)$ & $154(56.2)$ \\
\hline No & $202(43.2)$ & $82(42.5)$ & $120(43.8)$ \\
\hline \multicolumn{4}{|l|}{ Social support in South Africa } \\
\hline Yes & $371(79.4)$ & $149(77.2)$ & $222(81.0)$ \\
\hline No & $96(20.6)$ & $44(22.8)$ & $52(19.0)$ \\
\hline \multicolumn{4}{|l|}{ Ever had sexual intercourse } \\
\hline Yes & $439(94.0)$ & $182(94.3)$ & $257(93.8)$ \\
\hline No & $28(6.0)$ & $11(5.7)$ & $17(6.2)$ \\
\hline \multicolumn{4}{|c|}{ Information about family planning 6 months prior to survey } \\
\hline Yes & $264(60.0)$ & $83(43.0)$ & $195(71.2)$ \\
\hline No & $176(40.0)$ & $110(57.0)$ & $79(28.8)$ \\
\hline \multicolumn{4}{|l|}{ Current use of family planning } \\
\hline Yes & $358(81.4)$ & $143(74.1)$ & $215(78.5)$ \\
\hline No & $82(18.6)$ & $50(25.9)$ & $59(21.5)$ \\
\hline
\end{tabular}

Figure 1 shows the different sources of information on SRH among sexually active respondents disaggregated by gender. The main sources of information on SRH among all respondents were television and radio (38.7\%), friends (22.8\%) and poster (21.2\%). Community clinic and government hospital were $11.6 \%$ and $9.1 \%$ respectively. Similarly, among the females, the main sources of information on SRH were television and radio (45.9\%), friends (29.6\%) and poster (24.1\%); while only $15.6 \%$ and $10.5 \%$ of females sourced information about SRH issues from the community clinic and government hospital respectively. Among the males however, almost three out of 10 got information about family planning from television or radio 
(28.6\%), while $13 \%$ relied on friends. Only a small proportion of males received information on SRH from the community clinic (6\%) and government hospital (7\%).

The distribution of the two outcome variables among sexually active respondents is shown in Table 2. Over half (53.8\%) of the respondents had adequate KFP methods and only 4 out of $10(41.7 \%)$ reported having had access to government health facilities for SRH services. Gender differences exist in the two outcome variables. As far as KFP was concerned, one-third of the males and two-thirds of females had adequate KFP ( $p=0.000$ ). Regarding access to government health facilities for SRH services, only 1 out of 4 males and a little over half of females reported having had access for SRH services (0.000).

Table 2

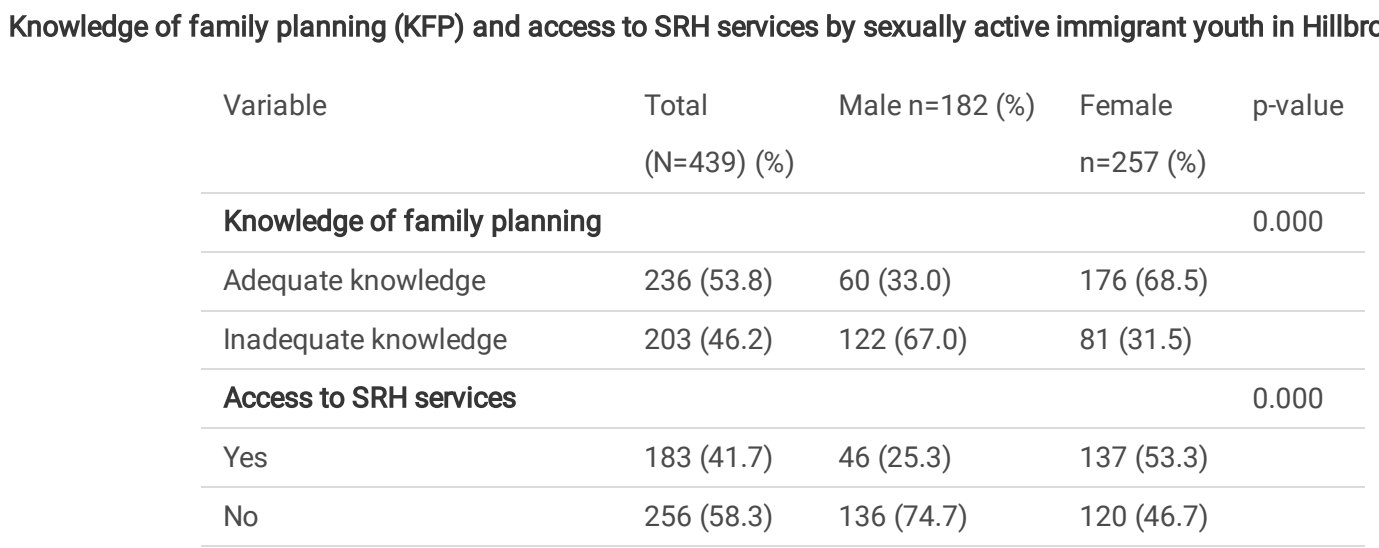

* $\mathrm{p}$-value for differences between males and females

\section{Knowledge of family planning among sexually active immigrant youth}

The results of crude and unadjusted logistic regression show the factors associated with, and the determinants of having KFP among sexually active immigrant youth. An additional Table file shows this in more detail [see Additional file 1]. Among all respondents, the females were more likely to have KFP (OR: 4.41, $\mathrm{Cl}=2.94-6.63 ; \mathrm{AOR}: 3.85, \mathrm{Cl}=2.33-6.35)$. Respondents in the age groups 25-29 years and 30-34 years were more likely to have KFP compared to those aged 18-24 years; (OR:1.75, $\mathrm{Cl}=1.10-2.78 ; \mathrm{AOR}: 2.13, \mathrm{Cl}=1.12-4.04)$ and (OR:2.54, $\mathrm{Cl}=1.60-4.03 ; \mathrm{AOR}: 3.88, \mathrm{Cl}=2.00-7.53)$ respectively. Regarding wealth index, respondents in the middle and rich wealth quintiles were more likely to have KFP compared with poor respondents (OR: 2.33 , $\mathrm{Cl}=1.51-3.61$; AOR: 1.84, $\mathrm{Cl}=1.05-3.20)$ and (OR: 3.45, $\mathrm{Cl}=2.05-5.80 ; \mathrm{AOR}: 2.61, \mathrm{Cl}=1.34-5.08)$ respectively. Not having received information about family planning 6 months prior to the survey reduced the odds of having KFP (OR: $0.11, \mathrm{Cl}: 0.07-0.17 ; \mathrm{AOR}: 0.16, \mathrm{Cl}=0.09-0.28)$. Not using a family planning method at the time of the survey reduced the odds of having knowledge about family planning $(0 \mathrm{R}: 0.42, \mathrm{Cl}=0.25-0.69 ; \mathrm{AOR}: 0.36, \mathrm{Cl}=0.18-$ 0.70).

Among the males, respondents in the age groups 30-34 years were more likely to have KFP compared to those aged 18-24 years (OR:3.71, $\mathrm{Cl}=1.75-7.86$; AOR:5.55, $\mathrm{Cl}=1.78-17.31)$. Not having received information about family planning 6 months prior to the survey reduced the odds of having KFP (OR: 0.11 , $\mathrm{Cl}$ : $0.05-0.24$; AOR: $0.14, \mathrm{Cl}=0.05-0.34)$. Not using a family planning method at the time of the survey reduced the odds of having KFP (OR: 0.17 ,

$\mathrm{Cl}=0.05-0.50)$; $\mathrm{AOR}: 0.1, \mathrm{Cl}=0.02-0.46)$.

Among the females, respondents in the age groups 30-34 years were more likely to have KFP compared to those aged 18-24 years (OR:2.69, Cl=1.385.23; AOR:3.07, $\mathrm{Cl}=1.31-7.21)$. Regarding wealth index, respondents in the middle and rich wealth quintiles were more likely to have KFP compared with the poor respondents (OR: 2.46, $\mathrm{Cl}=1.34-4.50$; $\mathrm{AOR}: 2.11, \mathrm{Cl}=1.03-4.34)$ and (OR: 3.44, $\mathrm{Cl}=1.62-7.29 ; \mathrm{AOR}: 3.35, \mathrm{Cl}=1.30-8.64)$ respectively. $\mathrm{Not}$ having received information about family planning 6 months prior to the survey reduced the odds of having KFP among the females (OR: 0.16 , Cl: $0.08-0.29$; AOR: $0.17, \mathrm{Cl}=0.08-0.36)$.

\section{Access to SRH services from government health facilities by sexually active immigrant youth in Hillbrow, South Africa}

The crude and adjusted logistic regression results show the factors and determinants of access to SRH services from government health facilities by sexually active immigrant youth. An additional Table file shows this in more detail [see Additional file 2. Among all the respondents, females are more likely to have access to government health facilities for SRH services compared to males (OR: $3.37, \mathrm{Cl}=2.23-5.10 ; \mathrm{AOR}$ : 2.95, $\mathrm{Cl}=1.87-4.65)$. Respondents in the age group 30-34 years are more likely to have access to government health facilities for SRH services compared to people in the age group 18-24 years (OR: 1.98, $\mathrm{Cl}=1.25-3.14$; AOR:1.91, $\mathrm{Cl}=1.08-3.39)$. Respondents who did not receive information about family planning 6 months prior to the survey had reduced the odds of having access to government health facilities for $\mathrm{SRH}$ services (OR: $0.28, \mathrm{Cl}=0.18-0.43 ; \mathrm{AOR}: 0.44, \mathrm{Cl}=0.27-0.73$. 
Among the males, having completed secondary education and higher was associated with access to government health facilities for SRH services (OR: $2.76, \mathrm{Cl}=1.19-6.38$ ), but the AOR was not significant at $5 \%$ level of significance (AOR: $2.52, \mathrm{Cl}=0.98-6.47$ ). Among the female respondents, those who were married or living with a partner were more likely to have access to government health facilities for SRH services (OR: 2.28, Cl=1.35-3.83; AOR: 2.13, $\mathrm{Cl}=1.12-4.07$ ). Females who did not receive information about family planning 6 months prior to the survey had reduced the odds of having access to government health facilities for SRH services (OR: $0.26, \mathrm{Cl}=0.14-0.47$; AOR: $0.28, \mathrm{Cl}=0.14-0.57$.

\section{Discussion}

This study examined the determinants of KFP and access to SRH services provided by government health facilities among sexually active immigrant youth in Hillbrow, South Africa. The study identified inadequate KFP and lack of access to SRH services from government health facilities in Hillbrow amongst the study participants. It further showed that majority of the participating immigrant youth sourced information about SRH issues from unreliable sources. The study participants did not get information about SRH from the government health facilities, all within walking distance from their place of residence. This finding is of concern because of the social environment of Hillbrow, which consist of a mix of internal migrants, non-migrants, and international migrants; lots of social activities including risky sexual behaviours and alcohol consumption [27]. Lack of access to correct, reliable information about SRH issues resulted in poor KFP. Lack of access to government health facilities for SRH services by sexually active immigrant male and female youth will lead to increase in negative SRH outcomes including STIs, re-infections, HIV infections, unplanned and unwanted pregnancies, unsafe abortions, and maternal mortality in Hillbrow, because sexual relationships among youth in Hillbrow does not respect migration status.

Lack of access to government health facility is consistent with previous qualitative studies among immigrants in South Africa, which indicate barriers to accessing SRH services by immigrants [19-21]. The observed gender differences with more males than females lacking KFP and lower access to SRH services in government health facilities may be because more females seek SRH information and services due to pregnancy and childbearing needs. Poor access to SRH services by men has been documented [28].

Participants in the group with a higher wealth index have better KFP, but do not have access to government health facilities. This indicates that the higher income group acquire knowledge about SRH from affordable sources other than government health facilities. Despite the availability of youth friendly SRH services for adolescents and youth under 25 years of age in Hillbrow, this study shows that immigrant youth aged 18-24 lacked KFP and physical access to SRH services. This study further shows that irrespective of migration status, both documented and undocumented immigrant youth in Hillbrow lacked access to government health facilities for SRH services. Qualitative study among the study population will provide a better understanding.

The association between not having received any information about family planning six months prior to the survey and lack of both KFP and access to $\mathrm{SRH}$ services underscore the importance of education, information, and communication about family planning among immigrants in Hillbrow. Previous studies in South Africa have recorded poor information about SRH services and products among immigrants [8, 25, 29-32].

The finding that immigrant youth who were not using a contraceptive method at the time of the survey lacked KFP showed the importance of KFP preceding actual use. This is consistent with findings by researchers elsewhere that showed that current use of family planning was associated with KFP [18].

Furthermore, the findings that females and respondents in the older age group were more likely to have access to health facilities was consistent with previous studies [11,33]. Similarly, the Bersamin and colleagues found poor knowledge about accessing SRH services among young men [33]. Lack of access to government health facilities left immigrant youth in Hillbrow with no other choice other than to obtain SRH information from unreliable sources.

Qualitative studies are necessary to understand the reason for widespread lack of access to government health facilities by immigrant youth in Hillbrow. Though some authors [24] alluded to the fact that "South Africa's laws, policies and guidelines on contraceptive service provision in the public sector are progressive, comprehensive, and promote integrated, rights-based service delivery", this study has shown that immigrant youth living in Hillbrow lack access to necessary information and KFP as well as access to SRH services in government health facilities.

Lack of access to correct information, KFP and government health facilities by immigrant youth thus raises questions with regard to the policies and guidelines for universal access to SRH services in government health facilities, especially in a migrant-dense community such as Hillbrow. There is need therefore to advocate for the culturally universal access to SRH services provided by government health facilities to curb the negative SRH outcomes, which will prevent South Africa from meeting its health targets, especially SDG 3.7 and 5.6 .

\section{Abbreviations}

SRH: Sexual and reproductive health

KFP: Knowledge of family planning

SDGs: Sustainable Development Goals

STIs: Sexually transmitted infections

HIV/AIDS: Human immunodeficiency virus/Acquired immune deficiency syndrome 


\section{Declarations}

\section{Acknowledgements}

We are grateful for the support from the staff of Population and Demography Department, North-West University, Mafikeng. Our gratitude goes to Mr Mashilo Philemon Mokgesi of Ikageng Community Development; Ms Brenda Lombard, the data collectors and more importantly, the migrants who participated in this study.

\section{Funding}

Funding support was provided by the Research Office of the North-West University, Mafikeng Campus.

\section{Availability of data and materials}

The datasets generated during and/or analysed during the current study are available from the corresponding author on reasonable request

\section{Ethics approval and consent to participate}

Ethics approval was granted by the Human and Social Sciences Research Ethics Committee:

NWU-01909-19-S7. Consent to participate was obtained from study participants.

\section{Competing interests}

The authors declare that they have no competing interests.

\section{Consent for publication}

\section{Authors' contributions}

NO and IK conceptualized and designed the study. NO analysed the data, MP and IK contributed to the interpretation of the data and made substantive revision to the manuscript.

\section{References}

1. United Nations: Report of the International Conference on Population and Development, Cairo, 5-13 September 1994. 1995. A/CONF.171/13/Rev.I.

2. United Nations Department of Economic and Social Affairs: World Conference on Youth, 2014. Colombo Declaration on Youth: Mainstreaming Youth in the Post-2015 Development Agenda. 2014. https://www.youthpolicy.org/library/wpcontent/uploads/library/2014_Colombo_Declaration_On_Youth_With_Annex_En.pdf

3. United Nations General Assembly: Transforming our World: The 2030 Agenda for Sustainable Development. 2015. A/RES/70/1. https://sustainabledevelopment.un.org/content/documents/21252030\%20Agenda\%20for\%20Sustainable\%20Development\%20web.pdf

4. United Nations: Youth and the 2030 agenda for sustainable development. World Youth Report. 2018. elSBN: 978-92-1-363256-7. https://www.un.org/development/desa/youth/wp-content/uploads/sites/21/2018/12/WorldYouthReport-2030Agenda.pdf

5. United Nations. International Migrant Stock 2019. Department of Economic and Social Affairs. Population Division (United Nations database, POP/DB/MIG/Stock/Rev.2019).

6. Statistics South Africa: Census 2011, Census in brief.Report no.: 03-01-41. 2012:105.

7. International Organization for Migration. International Migration Law. Glossary on Migration. 2019, 34. ISSN $1813-2278$.

8. Freedman J, Crankshaw TL, Mutambara VM: Sexual and reproductive health of asylum seeking and refugee women in South Africa: understanding the determinants of vulnerability. Sexual and Reproductive Health Matters. 2020, 28(1):1758440. https://doi:10.1080/26410397.2020.1758440.

9. Andersen RM: Revisiting the Behavioural Model and Access to Medical Care: Does it Matter? Journal of Health and Social Behaviour. 1995, 36(1):110. https://doi:10.2307/2137284.

10. Yang PQ, Hwang SH: Explaining Immigrant Health Service Utilization: A Theoretical Framework.SAGE Open. 2016, 6(2):2158244016648137. https://doi:10.1177/2158244016648137.

11. Ngum Chi Watts MC, McMichael C, Liamputtong P: Factors Influencing Contraception Awareness and Use: The Experiences of Young African Australian mothers.Journal of Refugee Studies, 2015, 28(3):368-387. http://doi:10.1093/jrs/feu040. 
12. Okoro ON, Whitson, SO: HIV risk and barriers to care for African-born immigrant women: a sociocultural outlook.International Journal of Women's Health. 2017, (9):421-429. http://doi:10.2147/IJWH.S129355.

13. Lee W, Neo A, Tan S, Cook AR, Wong ML, Tan J, Sayampanathan A, Lim D, Tang SY, Leong Goh WL, Chen MI, Ho C: Health-seeking behaviour of male foreign migrant workers living in a dormitory in Singapore.BMC Health Services Research. 2014, 14:300. http://www.biomedcentral.com/1472$6963 / 14 / 300$.

14. Alarcão V, Stefanovska-Petkovska M, Virgolino A, Santos O, Costa A: Intersections of Immigration and Sexual/Reproductive Health: An Umbrella Literature Review with a Focus on Health Equity.Social Sciences. 2021, 10:63. https://doi.org/10.3390/socsci 10020063

15. Alwan RM, Kaki DA, Hsia RY: Barriers and Facilitators to Accessing Health Services for People Without Documentation Status in an Anti-Immigrant Era: A Socioecological Model.Health Equity. 2021, 5.1. https://doi:10.1089/heq.2020.0138.

16. Giorgio M, Townsend L, Zembe Y, Cheyip M, Guttmacher S, Kapadia F, Mathews C: The Relationship between Social Support, HIV Serostatus, and Perceived Likelihood of being HIV Positive among Self-Settled Female, Foreign Migrants in Cape Town, South Africa.Journal of Immigrant and Minority Health. 2017, 19(4):883-890. https://doi:10.1007/s10903-016-0514-z.

17. Agu J, Lobo R, Crawford G, Chigwada B: Migrant Sexual Health Help-Seeking and Experiences of Stigmatization and Discrimination in Perth, Western Australia: Exploring Barriers and Enablers.International Journal of Environmental Research and Public Health. 2016, 13:485. https://doi:10.3390/ijerph13050485.

18. Åkerman E, Östergren PO, Essén B, Fernbrant C, Westerling R: Knowledge and utilization of sexual and reproductive healthcare services among Thai immigrant women in Sweden.BMC International Health and Human Rights. 2016, 16(1):25. https://doi:10.1186/s12914-016-0100-4.

19. Zihindula G, Meyer-Weitz A, Akintola O: Access to Health Care Services by refugees in Southern Africa: A Review of Literature.Southern African Journal of Demography. 2015, 16(1):7-35.

20. Rade DA, Crawford G, Lobo R, Gray C, Brown G: Sexual Health Help-Seeking Behavior among Migrants from Sub-Saharan Africa and South East Asia living in High Income Countries: A Systematic Review.International Journal of Environmental Research and Public Health. 2018, 15(7):1311. http://doi:10.3390/ijerph15071311.

21. Munyaneza Y, Mhlongo EM: Challenges of women refugees in utilising reproductive health services in public health institutions in Durban, KwaZuluNatal, South Africa. HEALTH SA GESONDHEID. Journal of Interdisciplinary Health Sciences, 2019, 24:1030. doi:10.4102/hsag.v24i0.1030

22. Mukondwa K, Gonah L: Accessing Adolescent Sexual and Reproductive Health Services among Undocumented Migrants in South Africa: A Documentary Review. Medical Journal of Zambia. 2016, 43(4):247-251.

23. Richter M, Chersich MF, Vearey J, Sartorius B, Temmerman M, Luchters, S: Migration Status, Work Conditions and Health Utilization of Female Sex Workers in Three South African Cities.Journal of Immigrant and Minority Health, 2014, 16(1), 7-17. doi:10.1007/s10903-012-9758-4.

24. Lince-Deroche N, Harries J, Mullick S, Mulongo M, Sinanovic E, Pleaner M, Morroni C, Firnhaber C, Holele P: Achieving universal access to sexual and reproductive health services: the potential and pitfalls for contraceptive services in South Africa.South African Health Review. 2016, 95-108.

25. International Organization for Migration (IOM) and the African Population and Health Research Centre (APHRC): Sexual and Reproductive Health and Rights in Selected Migration-affected Communities and Migration Corridors of East and Southern Africa: An in-depth analysis of policies, needs, barriers and rights to services. 2018. International Organization for Migration, Pretoria. https://migrationhealthsafrica.iom.int/sites/default/files/SRHR_Migration_Study_ESA_Oct_2018.pdf

26. National Department of Health. South Africa Demographic and Health Survey: Report, 2016. National Department of Health (NDOH), Statistics South Africa (Stats SA), South African Medical Research Council (SAMRC), and ICF.

27. Bello B, Moultrie H, Somji A, Chersich MF, Watts $C$, Delany-Moretlwe S: Alcohol use and sexual risk behaviour among men and women in inner-city Johannesburg, South Africa. BMC Public Health, 2017, 17(3), 548. doi:10.1186/s12889-017-4350-4.

28. Hardee K, Croce-Galis M, Gay J: Are men well served by family planning programs? Reproductive Hea/th. 2017, 14(1):14. https://doi:10.1186/s12978017-0278-5.

29. Crush J, Tawodzera G: Medical Xenophobia and Zimbabwean Migrants' Access to Public Health Services in South Africa. Journal of Ethnic and Migration Studies, 2014, 40(4), 655-670. doi:10.1080/1369183X.2013.830504

30. Hacker K, Anies M, Folb BL, Zallman L: Barriers to health care for undocumented immigrants: a literature review.Risk Management and Healthcare Policy. 2015, 8:175-183. https://doi:10.2147/RMHP.S70173.

31. Loganathan T, Chan ZX, de Smalen AW, Pocock NS: Migrant Women's Access to Sexual and Reproductive Health Services in Malaysia: A Qualitative Study.International Journal of Environmental Research and Public Health. 2020, 17:5376. http://doi:10.3390/ijerph17155376.

32. Msengi CM, Arthur-Okor H, Killion L, Schoer J: Educating immigrant women through social support. SAGE Open. October-December 2015:18. http://doi:10.1177/2158244015611935.

33. Bersamin M, Fisher DA, Marcell, AV, Finan, LJ: Deficits in young men's knowledge about accessing sexual and reproductive health services.Journal of American College Health. 2017, 65(8):579-584.

\section{Figures}






Figure 1

Sources of information about sexual and reproductive health issues by gender.

\section{Supplementary Files}

This is a list of supplementary files associated with this preprint. Click to download.

- Additionalfile1Table3.pdf

- Additionalfile2Table4.pdf 